\title{
Educação superior pública no Brasil: custos, benefícios e efeitos distributivos
}

Public higher education in Brazil: costs, benefits and distributive effects

Carlos Renato de Melo Castro (1)

Maria Eduarda Tannuri-Pianto (2)

(1) Secretaria do Tesouro Nacional Brasília-DF

(2) Universidade de Brasilia

\section{Abstract}

This paper addresses one aspect of equity: income, associated with the access to and funding of public universities in Brazil. As in other countries, the usual perception is that Brazilian public universities are free and attended mainly by high income students. In line with Barbaro (2005), considering the main public spending with higher education and the related tax costs, we estimate a net benefit by income decile. We observe for Brazil a net transfer of the richest $20 \%$ to the rest of the population and a concentration of net benefit in the 4 th to the 7 th decile range of per capita household income. Therefore, considering only the public budget for higher education, this net transfer would not reach the poorest $30 \%$ of the population, but it would still mitigate the significant inequality of Brazilian income.

\section{Keywords}

higher education, income equity, public spending.

JEL Codes H52, I23, I24, D30.

\section{Resumo}

O presente artigo se propõe a mensurar, por faixas de renda, quem são os financiadores e os beneficiários do sistema de educação superior pública no Brasil e, assim, mensurar a magnitude da redistribuição associada ao financiamento público dessa modalidade educacional. Como em outros países, a percepção usual é que as universidades públicas brasileiras são gratuitas e usufruídas principalmente pelas classes de maior rendimento. Na linha de Barbaro (2005), ao incluir os principais gastos públicos relacionados à educação superior e os respectivos custos tributários, estimamos um beneficio líquido por classe de renda. Observamos no caso brasileiro uma transferência líquida dos 20\% mais ricos para o restante da população e uma concentração desse benefício líquido no intervalo do 40 ao 70 decil de renda domiciliar per capita. Portanto, considerando apenas o orçamento público relativo ao ensino superior, essa transferência líquida atenuaria a significativa desigualdade de renda brasileira.

\section{Palavras-chave}

ensino superior, equidade de renda, gasto público.

Códigos JEL H52, I23, I24, D30. 


\section{Introdução}

Ao observarmos o modelo de provisão de educação superior no Brasil, com acesso limitado às universidades públicas, tradicionalmente de melhor qualidade, cabe uma discussão sobre a forma de financiamento desse modelo, seus principais beneficiários e suas implicações redistributivas. O primeiro ponto a discutir é se existe justificativa para o financiamento público da educação superior. A princípio, isso só se justificaria se os benefícios marginais sociais da educação superior fossem maiores que seus benefícios privados. A dificuldade é medir o valor desses benefícios. Existem algumas evidências de externalidades derivadas de educação superior e pode-se até suspeitar de que essas não são distribuídas uniformemente pelas classes de renda. Isso justificaria pelo menos alguma provisão pública de educação superior. Ademais, existem comprovadas externalidades associadas à pesquisa e uma parte substancial dos recursos destinados às universidades públicas tem essa destinação.

O segundo ponto seria então discutir se os gastos com educação superior são financiados de forma equitativa. Quanto a esse aspecto, é importante ter em mente que o governo, fazendo uso do sistema tributário para gerar receitas, deve ser capaz de utilizar as transferências públicas para redistribuir renda. Alguns trabalhos, como Immervoll et al. (2006) e Carvalho et al. (2013), evidenciam que o sistema tributário brasileiro é apenas levemente regressivo e que grande parte dos impostos pagos pelas classes de renda mais altas retornam para elas mesmas sob a forma de transferências ou serviços, ou seja, as transferências públicas têm um fraco caráter distributivo. Este artigo se propõe a mensurar, por faixa de renda, quem são os financiadores e os beneficiários do sistema de educação superior pública no Brasil e, portanto, mensurar a magnitude da redistribuição associada ao financiamento público dessa modalidade educacional. Podemos adiantar que, se considerarmos apenas essa modalidade de gasto público, famílias situadas entre o quarto e o sétimo decis de renda são as principais beneficárias líquidas do atual sistema de financiamento público da educação superior.

A recente expansão do ensino superior no Brasil teve taxas de crescimento médio das matrículas de $5 \%$ ao ano de 2009 a 2012. Com $45 \%$ das novas matrículas, a rede pública teve que fazer um esforço de expansão bastante superior ao da rede privada, já que esta ainda possuía, em 2012, mais do que o dobro das matrículas da rede pública. Uma questão natural 
é como esse processo de expansão tem evoluído em termos de equidade. As metas presentes no novo Plano Nacional de Educação para as taxas de escolarização do ensino superior são expressivas. Assim, torna-se também importante a discussão acerca da alocação do volume significativo de novos recursos públicos previstos para financiamento dessas metas.

Segundo Santiago et al. (2008), equidade em educação possui duas dimensões. A primeira é a justiça, que implica garantir que circunstâncias sociais e pessoais - tais como gênero, situação socioeconômica ou raça - não sejam obstáculos para o desenvolvimento do seu potencial educacional. A segunda é a inclusão, que implica garantir um padrão mínimo de educação para todos, ou seja, que qualquer um seja capaz de ler, escrever e dominar a aritmética simples. As duas dimensões são fortemente relacionadas: o ataque às deficiências escolares colabora para a transposição das privações sociais que, por sua vez, também implicam o fracasso escolar.

Mais especificamente, sistemas de ensino superior com equidade são aqueles para os quais se assegura que o acesso, a participação e os resultados estejam baseados apenas na habilidade inata do indivíduo e no seu esforço como estudante. Ele garante que a aquisição de educação em nível superior não seja resultado de circunstâncias sociais e pessoais, incluindo fatores como situação socioeconômica, gênero, etnia, status de imigrante, local de residência, idade ou doença.

O presente trabalho aborda uma das facetas da equidade: a renda. Como a oferta de educação superior pública no Brasil está distribuída pelas diversas classes de renda. Assim como em outros países, a percepção usual no Brasil é de que as universidades públicas e gratuitas são usufruídas principalmente pelas classes de maior rendimento e, portanto, os mais pobres estariam financiando os mais ricos. No caso do Brasil, essa discussão se impõe com mais veemência, dada a distância entre o gasto por aluno da educação básica e o da educação superior. Segundo o INEP, o gasto por aluno da educação superior era 4,8 vezes o gasto por aluno da educação básica, em 2011. Esse indicador mostra-se bastante superior ao observado internacionalmente. Os gastos com educação superior no Brasil também são significativos na comparação com outros tipos de despesa.

Na linha de Barbaro (2005), ao incluir os principais gastos públicos relacionados à educação superior e os respectivos custos tributários, estimamos um benefício líquido por classe de renda. Esse indicador nos permite avaliar quais classes de renda são mais beneficiadas. 
Este artigo está organizado em cinco seções. A próxima seção apresenta a literatura relacionada, e, com base nela, a terceira seção discute a metodologia adotada para cálculo do benefício líquido por classe de renda que advém do modelo de provisão da educação superior pública no Brasil. Ainda na terceira seção, descrevemos os dados e as proxies utilizadas, bem como debatemos a dependência dos resultados ao perfil da carga tributária brasileira, e à distribuição dos estudantes. A quarta seção discute os resultados e, a partir deles, é possível avaliar o padrão de transferência líquida entre as diversas classes de renda. A última seção conclui.

\section{Literatura}

Friedman (2009) afirma que a educação superior pública produz uma distribuição de renda perversa. A intuição relaciona-se com o processo de seleção e alocação dos estudantes, dado que os filhos de famílias com maior renda são selecionados com maior probabilidade relativamente àqueles de menor renda.

"Não conhecemos nenhum programa de governo que nos pareça tão injusto em seus efeitos, um exemplo tão claro da Lei de Director, quanto o financiamento do ensino superior. Nesta área, aqueles de nós que estão nas classes de renda média e alta ludibriaram os pobres para nos subsidiarem em grande escala - mas não apenas não temos nenhuma vergonha, nós nos vangloriamos para todos de nossa abnegação e espirito público." (Friedman e Friedman, 1990) (Tradução dos autores). ${ }^{1}$

O primeiro trabalho empírico sobre o impacto distributivo da educação superior pública foi realizado por Hansen e Weisbrod (1969). Nesse artigo, eles mostram que as famílias mais pobres na Califórnia recebem menos transferências via educação superior do que as famílias mais ricas, mesmo considerando que eles contribuem menos em termos de tributos que mantêm as universidades públicas.

Pechman (1970) foi o primeiro a se opor a essa tese. Ele argumenta que em nenhum ponto Hansen e Weisbrod (1969) comparam os benefícios e custos da educação superior pública em diferentes níveis de renda, como eles sugerem. Sua comparação foi realizada entre benefícios e tributos pa1 We know of no government program that seems to us so inequitable in its effects, so clear an example of Director's Law, as the financing of higher education. In this area those of us who are in the middle and upper-income classes have conned the poor into subsidizing us on the grand scale-yet we not only have no decent shame, we boast to the treetops of our selflessness and public-spiritedness (Friedman; Friedman, 1990). 
gos na média de famílias com e sem filhos matriculados no sistema da Califórnia. Além disso, o autor demonstra que os dados de Hansen e Weisbrod (1969) poderiam ser retrabalhados de modo a levar a um resultado progressivo. A partir daí essa discussão ficou conhecida como HansenWeisbrod-Pechman debate.

Um cálculo similar, baseado nos mesmos dados, foi realizado por McGuire (1976). Ele argumentou que o chefe do grupo familiar utilizado na base de dados deveria ter de 36 a 60 anos para melhor comparação em termos de renda e que os auxílios financeiros ao estudante deveriam ser considerados entre os benefícios. Com isso, ele conclui que os estudantes de famílias com menor renda seriam mais beneficiados do que aqueles de maior renda.

Machlis (1973) para Nova Iorque, Fields (1975) para o Quênia, Crean (1975) para o Canadá, Merz (1982) para a Suíça, James (1987) para o Japão e Lemelin (1992) são exemplos de estudos empíricos sobre o mesmo tema. Todos eles usam um cálculo de transferência líquida. Com exceção de Fields (1975), que apresenta os grupos de renda média como os principais beneficiados, e Lemelin (1992), que encontra um impacto regressivo quando a educação dos pais é usada para definir a posição social das famílias, todos os outros autores concluem por incidência proporcional.

Entre estudos um pouco mais recentes, Khan (1991) mostra que a incidência tributária e os subsídios à educação superior existentes no Paquistão geram uma redistribuição das classes média e superior de renda para os grupos de baixa renda. Soo Lee et al. (1999) também mostram que as classes baixa e média são as mais favorecidas no sistema público de educação superior de Illinois, em 1989. Eles comparam também as diferenças observadas entre universidades e faculdades comunitárias, destacando que, nestas, os principais beneficiários pertencem à classe de renda média. Já Lemelin (1992) não rejeita a hipótese de regressividade no financiamento público da educação superior em Quebec, usando dados de 1984, e constata que as famílias cujos chefes possuem maior escolaridade realizam os maiores ganhos. Gonzalez Rozada e Menendez (2002) estudam questões de eficiência e equidade na educação superior da Argentina. $O$ público atendido pertence principalmente aos decis superiores da distribuição da renda e às famílias com maior grau de escolaridade. Cerca de $90 \%$ dos estudantes das universidades públicas têm renda per capita superior à renda mediana recebida pelas famílias argentinas. Caner e Okten (2013), utilizando um modelo de três estágios e dados da Turquia, estima o subsídio recebido por 
estudante das universidades públicas e conclui que este é positivamente relacionado com a renda e o nível educacional da família. Eles constatam, também, que filhos de famílias com renda e educação superiores têm mais sucesso no exame de acesso à educação superior pública.

Grüske (1994) e Barbaro (2005), que aplicaram a metodologia do benefício líquido para a Alemanha, são as duas principais referências do nosso estudo. Em Grüske (1994), as famílias são classificadas através da renda familiar bruta anual. São considerados todos os benefícios recebidos pelos estudantes, tais como taxas, anuidades e outros. Os estudantes são associados à sua família de origem, que são classificadas em quatro grupos de renda (baixa, média, elevada e alta). A contribuição para financiar o gasto público da educação superior e a respectiva parcela sobre os pagamentos recebidos são determinados para cada parcela. No fim, seria possível determinar para cada grupo de renda se ele é um beneficiário líquido ou um contribuinte líquido do financiamento público da educação superior. Grüske (1994) encontra um efeito distributivo das famílias sem estudantes para aquelas com estudantes. Além disso, a distribuição entre as famílias com estudantes ocorre dos dois grupos de renda superior para os dois de renda inferior. Assim, aqueles benefícios que os dois grupos de renda superior não recebem têm um impacto especial, por exemplo, benefícios como o Bafog, que é um programa de assistência financeira a estudantes de menor renda. $\mathrm{O}$ autor distingue entre incidência líquida relativa e absoluta, que descrevem a diferença entre benefícios recebidos e a carga tributária. Para as faixas de renda mais baixas, os benefícios recebidos excedem a carga mais que cinco vezes. Se os efeitos líquidos absolutos são aplicados à renda bruta, a incidência é mais balanceada (distribuição do benefício líquido mais uniforme). Barbaro (2005) aprimora o trabalho de Grüske (1994) ao utilizar escalas de equivalência, ponderando, assim, as famílias de acordo com seu tamanho e ao determinar com maior precisão os benefícios tributários relacionados ao ensino. Os resultados apontam para uma distribuição do benefício líquido entre as classes de renda claramente a favor dos decis de menor renda.

\section{Metodologia e dados}

Neste artigo aplicamos metodologia desenvolvida por Grüske (1994) e Barbaro (2005) para calcular a transferência líquida entre classes de renda asso- 
ciada à estrutura tributária e à provisão do ensino superior público no Brasil. A ideia é classificar as famílias segundo sua renda e avaliar se cada grupo recebe mais ou menos benefícios do que paga em termos de tributos que mantêm o ensino superior público. O padrão dessas transferências líquidas depende da distribuição dos benefícios e da carga tributária. A distribuição dos benefícios, por sua vez, depende fundamentalmente da representação dos estudantes em cada classe. Destaque-se que uma das limitações metodológicas desta abordagem é não considerar esses aspectos distributivos ao longo de um ou mais ciclos de vida (ver Bevia; Iturbe-Ormaetxe, 2002; Hanushek et al. 2003; Bovenberg; Jacobs 2005 e o próprio Barbaro 2005, por exemplo). Aqui, os benefícios e custos são vistos de forma estática, ou seja, em um dado instante do tempo. As principais informações utilizadas neste trabalho foram obtidas nas seguintes bases de dados: Pesquisa Nacional por Amostra de Domicílios (PNAD-2012), Censo da Educação Superior/ INEP/Ministério da Educação (MEC), Sistema Integrado de Administração Financeira do Governo Federal (SIAFI) e Finanças do Brasil (FINBRA/STN). Além dessas bases, alguns documentos oficiais permitiram a construção de proxies para variáveis, entre os quais destacamos: Relatório de Gestão do Fundo de Financiamento Estudantil (FIES)/MEC, Relatório de Gestão da Secretaria de Educação Superior do MEC (SESU/MEC) e Relatório de Auditoria Operacional do Tribunal de Contas da União (TCU), 2009.

\subsection{Benefícios}

\subsubsection{Despesa federal}

A despesa empenhada pela União na subfunção Ensino Superior foi a base para definição dos benefícios ofertados em nível federal. Essas informações foram obtidas no Sistema Integrado de Administração Federal (SIAFI). Consideraram-se apenas as despesas relacionadas à graduação. Portanto foram excluídas despesas com os hospitais universitários e a concessão de bolsas, que são principalmente para a pós-graduação. As despesas com FIES e com o Plano Nacional de Assistência Estudantil (PNAES) foram consideradas separadamente, como veremos a seguir. Assim, o volume total de recursos assinalados como despesa federal correspondeu, em valores de 2012, a R $\$ 21,3$ bilhões. 
Conforme vemos na Tabela 1, são principalmente gastos com pessoal (70\%). No gasto com o custeio ordinário e com os investimentos, duas ações orçamentárias correspondem a quase $90 \%$ desses grupos de despesa: "Funcionamento das Universidades Federais" e "Reestruturação e Expansão das Universidades Federais (REUNI)".

Tabela 1 Gastos da União com ensino superior em 2012

\begin{tabular}{lrrr}
\hline Grupos de despesa & R\$ bilhão & Part. (\%) \\
\hline Pessoal & 14,9 & 70 \\
\hline Custeio & 3,9 & 18 \\
\hline Investimento & 2,4 & 11 \\
\hline Inversão & 0,03 & 0,1 \\
\hline Total & 21,3 & 100 \\
\hline
\end{tabular}

Fonte: SIAFI, 2012.

Considerando o total de 985.202 matrículas na rede federal, ${ }^{2}$ informado pelo Censo da Educação Superior de 2012, chegamos a um benefício médio anual por aluno, nessa rede, da ordem de $\mathrm{R} \$ 21.698,67$.

\subsubsection{Despesas estadual e municipal}

Segundo os dados divulgados pela Secretaria do Tesouro Nacional, as despesas dos estados e municípios em 2012, na subfunção Ensino Superior, foram de $\mathrm{R} \$ 7,5$ bilhões e $\mathrm{R} \$ 0,8$ bilhão, respectivamente. A indisponibilidade da desagregação dessas despesas em ações orçamentárias de uma forma computacionalmente tratável nos fez considerar toda ela como benefícios ofertados pelos entes subnacionais.

Considerando o total de 560.505 matrículas na rede estadual e de 170.045 na rede municipal, informados pelo Censo da Educação Superior de 2012, chegamos a um beneficio médio por aluno matriculado de $\mathrm{R} \$ 13.428,57$ nos estados e de $\mathrm{R}$ \$ 4.749,57 nos municípios.

Dessa forma, associaremos a cada família com aluno da rede pública de ensino superior um benefício $b g=17.317,19$, que corresponde à média ponderada dos valores por aluno na União, nos estados e nos municípios.

2 Consideramos apenas as matriculas presenciais que, em 2012, correspondiam a $90 \%$ do total das matrículas na rede pública federal. 


\subsubsection{FIES}

O Fundo de Financiamento Estudantil (FIES) é um programa destinado à concessão de financiamento a estudantes regularmente matriculados em cursos superiores não gratuitos e com avaliação positiva no MEC. É uma das principais ações para o cumprimento da meta do Plano Nacional de Educação relacionada às taxas de matrícula no nível superior.

Desde 1999, quando o FIES foi criado, o MEC vem promovendo alterações no programa, sendo as mais significativas aquelas promovidas pela Lei no 12.202/2010, que reduziu a taxa de juros e flexibilizou exigências de fiança, entre outras mudanças. Com isso, observou-se uma explosão na oferta do programa que teve que ser contida, dada a recente restrição fiscal brasileira. Para isso, alguns parâmetros foram redefinidos em 2015. Entre os quais se destacam a elevação da taxa de juros (6,5\% a.a.), a exigência de notas mínimas dos alunos no Exame Nacional do Ensino Médio (ENEM) (450 pontos) e a maior focalização da oferta em termos de renda. O percentual a ser financiado e as exigências de fiança continuam a privilegiar as classes de menor renda. Segundo o MEC, 78\% dos estudantes com FIES têm renda de até 1,5 salários-mínimos per capita.

O financiamento possui três fases: utilização, carência e amortização. A fase de utilização corresponde ao período do curso, quando ele paga trimestralmente, no máximo, R \$150,00 a título de juros. A carência é de 18 meses após a conclusão do curso para que ele recomponha seu orçamento. Nesse período continua pagando apenas a os R $\$ 150,00$ trimestrais. A quitação do financiamento, que se dá na fase de amortização, ocorre num prazo de três vezes o período financiado.

Existe ainda um benefício extra para professores e médicos que financiam seus cursos de graduação pelo FIES. Esses profissionais podem solicitar abatimento de $1 \%$ do saldo devedor por mês de efetivo exercício nas redes públicas de ensino e saúde, respectivamente. No caso dos docentes, o benefício vale para professores da educação básica pública com jornada de trabalho de, no mínimo, 20 horas semanais. Para os médicos, apenas aqueles que integrem equipes de saúde da família ou equipes que realizem atenção básica a quilombolas, indígenas, populações de assentamentos ou de regiões ribeirinhas em áreas definidas como prioritárias pelo Ministério da Saúde podem pedir o abatimento. Em ambos os casos, para solicitar o benefício é preciso comprovar o mínimo de um ano de trabalho ininterrupto. 
Segundo dados do Relatório de Gestão do FIES/MEC de 2012, a demanda por financiamento (Tabela 2) tem crescido significativamente:

Tabela 2 Contratos formalizados - FIES

\begin{tabular}{lr|r}
\hline Ano & $\mathbf{N}^{0}$ de contratos & Cresc. (\%) \\
\hline 2009 & 32.669 & - \\
\hline 2010 & 75.932 & $132 \%$ \\
\hline 2011 & 153.570 & $102 \%$ \\
\hline 2012 & 368.841 & $140 \%$ \\
\hline
\end{tabular}

Fonte: Relatório de Gestão FIES/MEC, 2012.

Em 2012, um total de 623.241 estudantes foi financiado ao custo de R\$ 5,18 bilhões. Aqui, são considerados os financiados em fase de utilização, ou seja, apenas os contratos daqueles que estão em sala de aula. Em uma análise no longo prazo, deveríamos considerar todos os contratos gerenciados, onde estariam inclusos também aqueles cujos estudantes já estariam formados, chegando a um total de 918.137 financiamentos. Além disso, em análise no longo prazo, poderíamos considerar também o retorno que o fundo tem quando o estudante amortiza a sua dívida. Considerando o escopo do presente estudo, em que nos restringimos ao período de um ano, consideramos como benefício exatamente o valor que o FIES transfere para a Instituição de Ensino Superior durante o período de utilização, que corresponde exatamente ao valor da mensalidade do curso. Dessa forma, consideramos como benefício por estudante a razão $\mathrm{R} \$ 5,18$ bilhões / 623.241 estudantes, que equivale a uma anuidade de $\mathrm{R} \$ 8.312,86$ e a uma mensalidade de $\mathrm{R} \$ 692,74$. Denominaremos essa anuidade de anuid:

$$
\text { anuid }=8.312,86
$$

Considerando que, em 2012, havia 4.208.086 matrículas no ensino superior privado, como informa o Censo da Educação Superior, concluímos que 14,81\% (623.241 / 4.2018.086 = 0,1481) destes possuíam FIES. Denominaremos tal percentual de parcfies:

$$
\text { parcfies }=0.1481
$$


O MEC informa que $82 \%$ dos beneficiários do FIES possuem renda familiar até cinco salários-mínimos. Denominaremos tal percentual de parcfies 5:

$$
\text { parcfies } 5=0,82
$$

Dados amostrais da PNAD indicam que $44,87 \%$ dos alunos do ensino superior privado possuíam renda familiar mensal de até cinco salários-mínimos. Denominaremos tal percentual de parc5:

$$
\operatorname{parc5}=0,4487
$$

Com essas informações atribuiremos a cada estudante do ensino superior privado, presente na PNAD, um benefício devido ao FIES. Associaremos o benefício a todos os estudantes da rede privada, pois não temos a informação na PNAD de que ele é beneficiário do FIES. Para tentar captar um pouco da distribuição por faixa de renda do benefício, faremos distinção se a renda familiar é inferior ou superior a cinco salários-mínimos. $O$ benefício para beneficiários do FIES com renda familiar até cinco salários-mínimos será calculado utilizando os parâmetros anteriores da seguinte forma:

$$
\begin{aligned}
& \text { benef } 5=\text { parcfies } 5 \times \text { anuid } \times \text { parcfies } x(1 / \text { parc } 5) \\
& \text { benef } 5=0,82 \times 8.312,86 \times 0,1481 \times(1 / 0,4487)=2.249,90
\end{aligned}
$$

Observemos que o cálculo anterior corresponde, como queríamos, à distribuição do gasto total com o programa entre os estudantes da rede privada. Para isso considere a seguinte notação:

- gasto5: gasto do FIES com estudantes com renda até $5 \mathrm{sm}$;

- n5: número de estudantes da rede privada com renda até $5 \mathrm{sm}$;

- n: número de estudantes da rede privada;

- gasto: gasto total do FIES;

- nfies: número de estudantes do FIES.

Considerando, inicialmente, o público com renda per capita de até cinco salários-mínimos, o gasto total do programa dividido pelos estudantes da rede privada com esse nível de renda é equivalente a: 


$$
\frac{\text { gasto } 5}{n 5}=\frac{\text { gasto } 5}{\text { gasto }} \times \frac{\text { gasto }}{n \text { fies }} \times \frac{\text { nfies }}{n 5}
$$

Os dois primeiros termos já foram denominamos de parcfies $5^{3}$ e anuid e o terceiro termo pode ser reescrito como:

$$
\frac{n \text { fies }}{n 5}=\frac{n \text { fies }}{n} \times \frac{n}{n 5}=\text { parcfies } x \frac{1}{\text { parc5 }}
$$

Com isso, mostramos que, para o público com renda per capita de até cinco salários-mínimos, o gasto total do programa dividido pelos estudantes da rede privada, ou seja, o benefício até cinco salários-mínimos, é equivalente:

$$
\begin{aligned}
& \frac{\text { gasto } 5}{n 5}=\text { parcfies } 5 \times \text { anuid } x \text { parcfies } x \frac{1}{\text { parc5 }} \\
& \text { benef } 5=0,82 \times 8.312,86 \times 0,1481 \times(1 / 0,4487)=2.249,90
\end{aligned}
$$

De modo similar, calculamos um benefício para os estudantes pertencentes às famílias com renda entre 5 e 20 salários-mínimos e chegamos a um valor de $\mathrm{R} \$ 453,90$.

\subsubsection{PROUNI}

O Programa Universidade para Todos (PROUNI) é destinado à concessão de bolsas de estudos integrais ou parciais (50\%) para estudantes de cursos de graduação em instituições privadas de ensino superior, com ou sem fins lucrativos. As instituições que aderem ao programa cumprindo uma proporção de bolsas prevista em lei fazem jus à isenção de tributos federais. $\bigcirc$ PROUNI, por não implicar gastos diretos para o Tesouro, constitui-se em uma ação extraorçamentária.

O programa é dirigido aos estudantes egressos do ensino médio da rede pública ou da rede particular na condição de bolsistas integrais, com renda

3 Utilizou-se a proporção entre o número de beneficiários como proxy para a aproximação da proporção entre os gastos. Naturalmente pode haver certa discrepância, mas que não comprometerá os principais resultados do artigo. 
familiar per capita máxima de três salários-mínimos. Os candidatos são selecionados pelas notas obtidas no Exame Nacional do Ensino Médio (Enem) e já atendeu, desde sua criação até o processo seletivo do segundo semestre de 2013, mais de 1,2 milhão de estudantes, sendo 69\% com bolsas integrais. Os beneficiários do PROUNI que possuem bolsa parcial desde 2005 têm prioridade na concessão de financiamento do montante não coberto pelo Programa por meio do FIES. Esse benefício, que era de até $50 \%$ do valor da mensalidade não coberto pela bolsa, foi ampliado com a possibilidade de financiamento de até $100 \%$.

Segundo o Relatório de Gestão da Secretaria de Educação Superior do MEC (SESU/MEC), em 2012, havia mais de 327 mil bolsas ativas, e o valor da renúncia fiscal, naquele ano, foi superior a $\mathrm{R} \$ 680$ milhões (Tabela 3).

Considerando esses números, poderíamos inferir que o valor médio de renúncia por bolsa em 2012 seria de $\mathrm{R} \$ 2.080,62$. Isso corresponderia a uma mensalidade de $\mathrm{R} \$ 173,38$, que é um valor bastante distante do valor médio de mensalidades cobrado pela rede privada de ensino superior.

Tabela 3 Bolsas e renúncia do PROUNI

\begin{tabular}{lrrr}
\hline Ano & Bolsas ativas & Renúncia fiscal (R\$) \\
\hline 2010 & 275.577 & 78.115 .899 \\
\hline 2011 & 298.173 & 633.329 .017 \\
\hline 2012 & 327.033 & 680.430 .7745 \\
\hline
\end{tabular}

Fonte: Relatório de Gestão SESU/MEC, 2012.

Segundo dados da consultoria Hoper Educação, que estão no documento "Análise Setorial do Ensino Superior Privado", a mensalidade média em 2012 seria de $\mathrm{R} \$ 518,15$. O referido relatório de gestão da SESU/MEC informa que:

(...) a renúncia fiscal decorrente do PROUNI afeta somente as instituições com fins lucrativos, tendo em vista que as instituições sem fins lucrativos não beneficentes e beneficentes de assistência social possuem tratamento tributário próprio, razão pela qual a renúncia fiscal das entidades sem fins lucrativos não se aloca ao Programa.

No ano de 2009, em relatório de auditoria operacional, o Tribunal de Contas da União (TCU) apresentou a mesma dificuldade em estimar esse indicador, dada as diferenças existentes no tratamento tributário das entidades com e sem fins lucrativos. Nesse sentido, o TCU solicitou à Secretaria da Receita Federal (SRF) que elaborasse uma estimativa mais apurada, conside- 
rando as especificidades de cada instituição. Com isso, a SRF informou que o custo médio mensal de cada bolsa PROUNI, em 2006, foi de R \$786,00.

Tabela 4 Custo bolsa mensal do PROUNI, 2006

\begin{tabular}{lr}
\hline Tipo de instituição & Custo \\
\hline Com fins lucrativos & 495,00 \\
\hline Sem fins lucrativos não beneficentes & 916,00 \\
\hline Sem fins lucrativos beneficentes & $1.043,00$ \\
\hline Total & 786,00 \\
\hline
\end{tabular}

Fonte: TCU, 2009.

Segundo o relatório elaborado pela consultoria Hoper, o tíquete médio, razão entre o faturamento e o número de matrículas, das instituições privadas de ensino superior, era de R \$ 550, em 2009, e R \$ 518,50, em 2012. Utilizando esse indicador para o valor de mercado das mensalidades, elaboramos uma proxy para o valor da renúncia fiscal do PROUNI por bolsa.

Observamos que, em 2009, o valor da renúncia era $43 \%$ superior ao valor da mensalidade média. Aplicando esse mesmo percentual ao valor da mensalidade média de 2012 ( $\mathrm{R} \$ 518,5$ ), chegamos a um valor de $\mathrm{R} \$ 743$ mensais, que em termos anuais correspondem a R \$ 8.916.

Novamente, como não temos a informação na PNAD de que o estudante do ensino superior privado é beneficiário do PROUNI, dividiremos o gasto total do programa igualmente a todos, focalizando nas famílias com renda per capita inferior a 1,5 salários-mínimos. De maneira similar ao cálculo feito para o FIES, o benefício será calculado da seguinte forma:

$$
\begin{aligned}
& \text { benprouni }=\text { anuid } \times \text { parcprouni } \times(1 / \text { parc1.5 }) \\
& \text { benprouni }=8.916 \times 0,078 \times(1 / 0,442)=1.571,64
\end{aligned}
$$

onde:

- benprouni: benefício atribuído a cada aluno da rede privada com renda até 1,5 sm;

- anuid: estimativa da renúncia tributária por aluno do PROUNI;

- parcprouni: percentual da rede privada com PROUNI;

- parc1.5: percentual de estudantes da rede privada com renda de até $1,5 \mathrm{sm}$. 
Como dissemos, a fórmula anterior vem da distribuição do gasto total do programa pelos estudantes da rede privada com renda de até 1,5 salários-mínimos. A equação obtida decorre da seguinte equivalência:

$$
\frac{\text { gasto }}{n 1.5}=\frac{\text { gasto }}{n \text { prouni }} \times \frac{n \text { prouni }}{n} \times \frac{n}{n 1.5}=\frac{\text { gasto }}{n \text { prouni }} \times \frac{\text { nprouni }}{n} \times \frac{1}{\frac{n 1.5}{n}}
$$

Naturalmente, os três fatores finais correspondem à equação utilizada para atribuir um benefício devido ao PROUNI:

$$
\frac{\text { gasto }}{n 15}=\frac{\text { gasto }}{\text { nprouni }} \times \frac{n \text { prouni }}{n} \times \frac{1}{\frac{n 15}{n}}=\text { anuidxparcprounix }(1 / \text { parc15) }
$$

\subsubsection{PNAES}

O Plano Nacional de Assistência Estudantil (PNAES) é um programa direcionado à permanência de estudantes de baixa renda matriculados em cursos de graduação presencial das instituições federais de ensino superior. O PNAES atua na assistência à moradia estudantil, à alimentação, ao transporte, entre outras áreas. Os critérios de seleção dos estudantes levam em conta o perfil socioeconômico dos alunos, sendo que, por força do Decreto no 7.234 de 19 de julho de 2010, devem ser atendidos prioritariamente estudantes oriundos da rede pública de educação básica ou com renda familiar per capita de até um salário-mínimo e meio.

Em 2012, 59 Universidades Federais receberam o montante de $\mathrm{R} \$$ 503.843.628,00 com a finalidade de oferecer condições de permanência aos estudantes em vulnerabilidade socioeconômica, conforme vemos na Tabela 5:

Tabela 5 Gasto PNAES

\begin{tabular}{l|r}
\hline Ano & R\$ milhões \\
\hline 2008 & 101,19 \\
\hline 2009 & 197,03 \\
\hline 2010 & 305,65 \\
\hline 2011 & 395,18 \\
\hline 2012 & 503,84 \\
\hline
\end{tabular}

Fonte: MEC.2008 a 2012. 
Assim como nos casos anteriores, considerando o total de matrículas da rede pública e a proporção de alunos com renda per capita inferior a 1,5 salários-mínimos, estimamos um valor de $\mathrm{R} \$ 1.022,42$ como benefício por aluno nas universidades públicas.

\subsection{Contribuições}

Estimamos a parcela de responsabilidade de cada família para o custeio dos bens públicos relacionados à educação superior. Consideramos para esse fim a parcela que o gasto público relacionado ao ensino superior representa na carga tributária suportada pelas famílias.

\subsubsection{Orçamento do ensino superior}

Ao olhar para os orçamentos públicos, citados anteriormente, temos que as despesas relacionadas ao ensino superior público ultrapassam $\mathrm{R} \$ 36$ bilhões (Tabela 6).

Tabela 6 Gasto no ensino superior público, 2012

\begin{tabular}{lr}
\hline Gasto & R\$ milhões \\
\hline União & $21.377,58$ \\
\hline Estados & $7.526,78$ \\
\hline Municípios & 807,64 \\
\hline FIES & $5.180,92$ \\
\hline PROUNI & 680,43 \\
\hline PNAES & 536,56 \\
\hline Total & $36.109,91$ \\
\hline
\end{tabular}

Fonte: Elaboração própria.

Quando aplicamos as proxies definidas anteriormente como benefícios individuais aos estudantes presentes na PNAD, onde excluímos também observações com problemas nos dados de renda, chegamos a um total de R $\$$ 34,9 bilhões. Isso indica, portanto, a razoabilidade das hipóteses adotadas. 


\subsubsection{Carga tributária}

Neste estudo, utilizamos a carga tributária estimada em Pintos-Payeras (2010) para auferir as transferências de cada indivíduo para o financiamento da educação superior. Nela, o autor verifica que o sistema tributário brasileiro é levemente regressivo quando tomamos como base a renda. Isso se deve em grande parte aos impostos indiretos, mais especificamente ao Imposto sobre Circulação de Mercadorias e Serviços (ICMS), ao Programa de Integração Social (PIS) e à Contribuição para Financiamento da Seguridade Social (Cofins). Esse estudo dá um passo significativo, pois apura as alíquotas de ICMS de cada estado, bem como os tratamentos diferenciados, tais como a redução da base de cálculo e a isenção dadas aos produtos constantes da Pesquisa de Orçamento Familiar (POF) de 2002-2003. Quando nenhum tratamento é dado às isenções e reduções na base de cálculo tende-se a superestimar a carga tributária indireta. No caso do ISS, devido à impossibilidade de levantar as alíquotas de todos os municípios do Brasil, foram escolhidas as capitais de cada unidade da federação. Na Tabela 7, apresentamos os percentuais obtidos naquele estudo e sua incidência sobre a renda apurada na PNAD.

Tabela 7 Carga tributária total sobre a renda familiar per capita

\begin{tabular}{lr|r|r}
\hline $\begin{array}{l}\text { Classes de renda } \\
\text { per capita (s.m.) }\end{array}$ & $\begin{array}{r}\text { Alíquotas carga } \\
\text { tributária (\%) }\end{array}$ & $\begin{array}{r}\text { Renda total } \\
\text { da classe (R\$ bi) }\end{array}$ & $\begin{array}{r}\text { Carga tributária total } \\
\text { da classe (RS bi) }\end{array}$ \\
\hline $\mathbf{0 - 0 . 5}$ & 22,99 & 122 & 28,0 \\
\hline $\mathbf{0 . 5 - 1}$ & 20,37 & 317 & 64,5 \\
\hline $\mathbf{1 - 1 . 5}$ & 19,55 & 276 & 54,0 \\
\hline $\mathbf{1 . 5 - 2}$ & 19,50 & 212 & 41,3 \\
\hline $\mathbf{2 - 2 . 5}$ & 19,32 & 157 & 30,4 \\
\hline $\mathbf{2 . 5 - 3}$ & 19,79 & 104 & 20,6 \\
\hline $\mathbf{3 - 4}$ & 20,12 & 146 & 29,3 \\
\hline $\mathbf{4 - 5}$ & 20,37 & 118 & 23,9 \\
\hline $\mathbf{5 - 6}$ & 19,75 & 74,3 & 14,7 \\
\hline $\mathbf{6 - 8}$ & 21,41 & 104 & 22,2 \\
\hline $\mathbf{8 - 1 1}$ & 20,53 & 106 & 21,8 \\
\hline $\mathbf{1 1 - 1 6}$ & 20,25 & 73,6 & 14,9 \\
\hline Acima de 16 & 17,29 & 131 & 22,7 \\
\hline Total & 19,79 & 1.940 & 388,0 \\
\hline
\end{tabular}

Fonte: Alíquotas extraídas de Pintos-Payeras (2010), e renda da PNAD, 2012. 
Observemos que a carga tributária estimada por Pintos-Payeras (2010) é apenas levemente regressiva ou quase neutra. Esse é um fato também evidenciado em outros estudos. Carvalho et al. (2013), por exemplo, estimou uma distribuição da carga tributária devida aos impostos indiretos, responsáveis pela regressividade do sistema tributário brasileiro, com pouca variação entre os décimos de despesa familiar per capita. Silveira et al. (2013) destaca a importância de se utilizar a renda total em vez da renda monetária já que esta sobre-estimaria o impacto dos tributos indiretos para o mais pobres. Com isso, Silveira et al. (2013) chega a uma distribuição também com pouca variação do segundo ao décimo decil (4 p.p.).

Por fim, se considerarmos que toda a despesa pública com ensino superior seja financiada pelas famílias, temos que o seu orçamento corresponde a $9 \%$ da carga tributária das famílias.

\subsubsection{Contribuição por família}

Cada família i será classificada segundo sua renda familiar per capita, $y_{i}$, numa das 13 classes possíveis, digamos a classe $j$, e a sua contribuição para o financiamento da educação superior pública, $p_{i}$, será definida como:

$$
p_{i}=0,09 t_{j} y_{i} n_{i}
$$

onde $t_{j}$ é a carga tributária da classe $j, n_{i}$ é o tamanho da família $i$ e 0,09 corresponde à parcela do total de tributos pagos pela família destinada ao ensino superior público.

\section{Resultados}

Apresentamos agora as distribuições das principais variáveis que nos permitem avaliar como se dá a transferência de benefícios entre as diversas classes de renda, que é o nosso objetivo final. Antes, evidenciamos, na Tabela 8, os valores de renda per capita familiar que caracterizam os limites de cada decil de renda, segundo PNAD, 2012, para qualificar a análise. 
Tabela 8 Decis de renda domiciliar per capita

\begin{tabular}{lrr}
\hline Decil & Renda domiciliar per capita (R\$) \\
\hline 1 & 181 \\
\hline 2 & 287 \\
\hline 3 & 383 \\
\hline 4 & 500 \\
\hline 5 & 622 \\
\hline 6 & 725 \\
\hline 7 & 933 \\
\hline 8 & 1.248 \\
\hline 9 & 2.000 \\
\hline 10 & - \\
\hline
\end{tabular}

Fonte: PNAD, 2012.

\subsection{Distribuição dos alunos}

De fato, observamos que cerca de $50 \%$ dos alunos das redes pública e privada estão nos últimos três decis de renda e que nos três primeiros não há sequer $10 \%$ deles (Tabela 9). Isso confirma que, realmente, os alunos do ensino superior no Brasil são majoritariamente das classes média e alta.

Tabela 9 Estudantes do ensino superior por decil de renda familiar per capita

\begin{tabular}{lrrrr|r|r|r|r}
\hline Decis & $\begin{array}{r}\text { Estudantes } \\
\text { rede pública }\end{array}$ & $\begin{array}{r}\text { Part. } \\
\mathbf{( \% )}\end{array}$ & $\begin{array}{r}\text { Estudantes } \\
\text { rede privada }\end{array}$ & $\begin{array}{r}\text { Part. } \\
\mathbf{( \% )}\end{array}$ & Total & $\begin{array}{r}\text { Part. } \\
\mathbf{( \% )}\end{array}$ & $\begin{array}{r}\text { Acum. } \\
\mathbf{( \% )}\end{array}$ \\
\hline $\mathbf{1}$ & 55.828 & 3,8 & 91.704 & 2,0 & 147.532 & 2,5 & 2,5 \\
\hline $\mathbf{2}$ & 73.720 & 5,0 & 103.536 & 2,3 & 177.256 & 3,0 & 5,4 \\
\hline $\mathbf{3}$ & 84.030 & 5,7 & 174.579 & 3,9 & 258.609 & 4,3 & 9,7 \\
\hline $\mathbf{4}$ & 131.342 & 9,0 & 309.133 & 6,8 & 440.475 & 7,3 & 17,1 \\
\hline $\mathbf{5}$ & 152.928 & 10,4 & 363.543 & 8,0 & 516.471 & 8,6 & 25,7 \\
\hline $\mathbf{6}$ & 108.558 & 7,4 & 325.123 & 7,2 & 433.681 & 7,2 & 32,9 \\
\hline $\mathbf{7}$ & 187.672 & 12,8 & 641.969 & 14,2 & 829.641 & 13,8 & 46,8 \\
\hline $\mathbf{8}$ & 190.540 & 13,0 & 723.170 & 16,0 & 913.710 & 15,2 & 62,0 \\
\hline $\mathbf{9}$ & 255.087 & 17,4 & 983.335 & 21,7 & 1.238 .422 & 20,7 & 82,7 \\
\hline $\mathbf{1 0}$ & 226.477 & 15,4 & 813.824 & 18,0 & 1.040 .301 & 17,3 & 100,0 \\
\hline Total & $\mathbf{1 . 4 6 6 . 1 8 2}$ & 100,0 & 4.529 .916 & 100,0 & 5.996 .099 & 100,0 & - \\
\hline
\end{tabular}

Fonte: PNAD, 2012. 


\subsection{Benefícios}

O benefício público geral obtido a partir dos orçamentos públicos federal, estadual e municipal tem distribuição idêntica àquela apresentada pelos estudantes da rede pública pelos decis de renda.

Os dados da PNAD 2012 informam que 45\% dos alunos estão nos três últimos decis. Portanto, quase metade desse benefício público geral (45\%), que é ofertado através das universidades públicas, está sendo usufruído pelos $30 \%$ mais ricos.

Os benefícios considerados específicos, por serem programas focalizados em termos de renda, naturalmente concentram-se nas primeiras classes. Com isso, somando os benefícios gerais e específicos, encontramos $38 \%$ deles concentrados na parcela da população com mais renda, conforme vemos nos decis 8, 9 e 10 da Tabela 10 .

Tabela 10 Benefícios orçamentários e específicos

\begin{tabular}{l|r|rr|r}
\hline Decil & $\begin{array}{r}\text { Orçamentário } \\
\mathbf{( R \$} \text { bi) }\end{array}$ & $\begin{array}{r}\text { Específico } \\
\mathbf{( R \$} \text { bi) }\end{array}$ & $\begin{array}{r}\text { Total } \\
\mathbf{( R \$} \text { bi) }\end{array}$ & $\begin{array}{r}\text { Part. } \\
\text { (\%) }\end{array}$ \\
\hline $\mathbf{1}$ & 0,96 & 0,40 & 1,37 & 3,9 \\
\hline $\mathbf{2}$ & 1,28 & 0,47 & 1,75 & 5,0 \\
\hline $\mathbf{3}$ & 1,46 & 0,75 & 2,21 & 6,3 \\
\hline $\mathbf{4}$ & 2,27 & 1,29 & 3,57 & 10,2 \\
\hline $\mathbf{5}$ & 2,65 & 1,48 & 4,13 & 11,8 \\
\hline $\mathbf{6}$ & 1,88 & 1,20 & 3,08 & 8,8 \\
\hline $\mathbf{7}$ & 3,25 & 2,15 & 5,40 & 15,5 \\
\hline $\mathbf{8}$ & 3,30 & 0,76 & 4,07 & 11,6 \\
\hline $\mathbf{9}$ & 4,42 & 0,73 & 5,15 & 14,7 \\
\hline $\mathbf{1 0}$ & 3,92 & 0,30 & 4,22 & 12,1 \\
\hline Total & 25,4 & 9,56 & 34,9 & 100,0 \\
\hline
\end{tabular}

Fonte: Elaboração própria.

\subsection{Contribuição}

A estimativa feita para o pagamento de tributos que financiariam a educação superior pública no Brasil é decorrente de dois fatores: a distribuição da carga tributária e a distribuição da renda. Como a carga tributária sobre a renda 
estimada por Pintos-Payeras (2010) resulta numa distribuição apenas ligeiramente regressiva, a distribuição do total de tributos pago por faixa de renda é muito próxima da distribuição da renda, conforme destacado na Tabela $11 .{ }^{4}$

Tabela 11 Renda e carga tributária

\begin{tabular}{l|rr|rr}
\hline Decil & $\begin{array}{r}\text { Renda total } \\
\text { (R\$ bi) }\end{array}$ & $\begin{array}{r}\text { Part. } \\
\text { (\%) }\end{array}$ & $\begin{array}{r}\text { Carga tributária } \\
\text { (R\$ bi) }\end{array}$ & $\begin{array}{r}\text { Part. } \\
\text { (\%) }\end{array}$ \\
\hline $\mathbf{1}$ & 30,2 & 1,6 & 6,9 & 1,8 \\
\hline $\mathbf{2}$ & 65,3 & 3,4 & 15,0 & 3,9 \\
\hline $\mathbf{3}$ & 82,0 & 4,2 & 17,4 & 4,5 \\
\hline $\mathbf{4}$ & 118,0 & 6,1 & 23,9 & 6,1 \\
\hline $\mathbf{5}$ & 144,0 & 7,4 & 29,3 & 7,5 \\
\hline $\mathbf{6}$ & 99,0 & 5,1 & 19,4 & 5,0 \\
\hline $\mathbf{7}$ & 177,0 & 9,1 & 34,6 & 8,9 \\
\hline $\mathbf{8}$ & 213,0 & 11,0 & 41,5 & 10,7 \\
\hline $\mathbf{9}$ & 314,0 & 16,2 & 61,6 & 15,9 \\
\hline $\mathbf{1 0}$ & 698 & 36,0 & 139,0 & 35,7 \\
\hline Total & 1.940 & 100 & 388,0 & 100 \\
\hline
\end{tabular}

Fonte: Elaboração própria, com base nas alíquotas extraídas de Pintos-Payeras, 2010, e renda da PNAD, 2012.

Tabela 12 Contribuição por decil de renda para financiamento da educação superior

\begin{tabular}{lrr}
\hline Decis & Contribuição (R\$ bi) & Part. \% \\
\hline $\mathbf{1}$ & 0,62 & 1,8 \\
\hline $\mathbf{2}$ & 1,35 & 3,9 \\
\hline $\mathbf{3}$ & 1,56 & 4,5 \\
\hline $\mathbf{4}$ & 2,16 & 6,2 \\
\hline $\mathbf{5}$ & 2,63 & 7,5 \\
\hline $\mathbf{7}$ & 1,74 & 5,0 \\
\hline $\mathbf{8}$ & 3,12 & 8,9 \\
\hline $\mathbf{9}$ & 3,74 & 10,7 \\
\hline $\mathbf{1 0}$ & 5,55 & 15,9 \\
\hline Total & 12,5 & 35,7 \\
\hline
\end{tabular}

Fonte: Elaboração própria.

4 Como consideramos a distribuição da renda domicilliar per capita, e não da renda domiciliar, e o total de pessoas observado no $6^{\circ}$ decil (dos domicílios) é significativamente inferior ao do $5^{\circ}$ decil, obtivemos uma renda total das pessoas no $6^{\circ}$ decil (dos domicilios) também inferior ao do $5^{\circ}$ decil. 
Por sua vez, como a contribuição é apenas uma fração constante da carga tributária que cada família suporta, observamos que a distribuição dos pagamentos relativos à educação superior seria idêntica à da carga tributária, que por sua vez é similar à da renda. Assim, a significativa desigualdade de renda do Brasil reflete-se na distribuição dos pagamentos. Observamos que mais de $50 \%$ destes estariam nos dois últimos decis de renda, conforme vemos nos decis 9 e 10 da Tabela 12 .

\subsection{Benefício líquido}

Considere que o benefício líquido é a diferença entre todos os benefícios relativos ao ensino superior e a parcela dos tributos pagos direcionada ao ensino superior. $O$ resultado obtido, destacado na Tabela 13 , indica transferência dos dois últimos decis de renda para os oito primeiros. Destaque-se que mais de $95 \%$ dessa transferência ( $\mathrm{R} \$ 8,2$ bi) é realizada pelo último decil, que corresponde às famílias que possuem renda familiar per capita superior a $\mathrm{R} \$ 2.000,00$ (3,2 salários-mínimos), em valores de 2012. Os principais beneficiários são as famílias que estão do 40 ao 7 o decil, com destaque para este último, com $\mathrm{R} \$ 2,2$ bilhões de benefício líquido.

Isto nos leva a concluir que os $10 \%$ mais ricos financiam o ensino superior público dos $80 \%$ mais pobres. Esse resultado contraria, em certa medida, o senso comum de que os bens públicos relacionados à educação superior seriam financiados principalmente pelos mais pobres e usufruídos pelos mais ricos. De fato, quando avaliamos a distribuição dos alunos do ensino superior no Brasil, segundo a $\mathrm{PNAD}$, observamos que os três últimos decis de renda concentram mais de $50 \%$ dos estudantes. Portanto as classes média alta e alta são as que têm maior participação na universidade brasileira. Porém, ao considerarmos os resultados obtidos para o benefício líquido, concluímos que o total de tributos pagos pelos mais ricos se sobrepuja a essa maior participação levando a uma transferência líquida dos dois últimos decis para o restante da população.Avaliamos também o papel dos programas focalizados, como FIES e PROUNI, nas classes de menor renda. Os benefícios desses programas se concentram do 40 ao 7 o decis e cumprem um papel importante de inclusão. Ressalte-se que, mesmo se os desconsiderarmos no total de benefícios, as famílias entre os decis 4 e 7 ainda são as que recebem o maior benefício líquido, conforme observamos na Tabela 14 . 
Tabela 13 Benefício Líquido

\begin{tabular}{|c|c|c|c|c|}
\hline Decis & $\begin{array}{r}\text { Benefício total } \\
\text { (R\$ bi) }\end{array}$ & $\begin{array}{r}\text { Contribuição } \\
\text { (R\$ bi) }\end{array}$ & $\begin{array}{r}\text { Benefício líquido } \\
\text { (R\$ bi) }\end{array}$ & $\begin{array}{l}\text { Ben. líq. / Total das } \\
\text { contribuições(\%) }{ }^{2^{5}}\end{array}$ \\
\hline 1 & 1,3 & 0,6 & 0,7 & 2,2 \\
\hline 2 & 1,7 & 1,3 & 0,4 & 1,1 \\
\hline 3 & 2,2 & 1,5 & 0,6 & 1,8 \\
\hline 4 & 3,5 & 2,1 & 1,4 & 4,0 \\
\hline 5 & 4,1 & 2,6 & 1,5 & 4,3 \\
\hline 6 & 3,0 & 1,7 & 1,3 & 3,8 \\
\hline 7 & 5,4 & 3,1 & 2,2 & 6,5 \\
\hline 8 & 4,0 & 3,7 & 0,3 & 0,9 \\
\hline 9 & 5,1 & 5,5 & $-0,4$ & $-1,1$ \\
\hline 10 & 4,2 & 12,5 & $-8,2$ & $-23,6$ \\
\hline Total & 34,9 & 34,9 & 0,00 & 0,0 \\
\hline
\end{tabular}

Fonte: Elaboração do autor.

Tabela 14 Benefício líquido sem FIES e PROUNI

\begin{tabular}{|c|c|c|c|c|}
\hline Decis & $\begin{array}{r}\text { Benefício total } \\
\text { (R\$ bi) }\end{array}$ & $\begin{array}{r}\text { Contribuição } \\
\text { (R\$ bi) }\end{array}$ & $\begin{array}{r}\text { Benefício líquido } \\
\text { (R\$ bi) }\end{array}$ & $\begin{array}{l}\text { Ben. líq. / Total das } \\
\text { contribuições (\%) }\end{array}$ \\
\hline 1 & 1,0 & 0,5 & 0,5 & 2,0 \\
\hline 2 & 1,3 & 1,0 & 0,3 & 1,2 \\
\hline 3 & 1,5 & 1,1 & 0,3 & 1,3 \\
\hline 4 & 2,3 & 1,6 & 0,7 & 2,8 \\
\hline 5 & 2,7 & 1,9 & 0,7 & 2,9 \\
\hline 6 & 1,9 & 1,3 & 0,6 & 2,4 \\
\hline 7 & 3,3 & 2,3 & 1,0 & 3,9 \\
\hline 8 & 3,3 & 2,7 & 0,6 & 2,3 \\
\hline 9 & 4,4 & 4,0 & 0,4 & 1,5 \\
\hline 10 & 3,9 & 9,1 & $-5,1$ & $-20,2$ \\
\hline Total & 25,4 & 25,4 & 0,00 & 0,0 \\
\hline
\end{tabular}

Fonte: Elaboração própria.

Destaque-se que esses resultados não se alteram se considerarmos as cargas tributárias estimadas em Carvalho (2013) e Silveira et al. (2013). Os

5 Representa o quanto que cada decil se beneficiou liquidamente do total que a sociedade pagou para ofertar a educação superior, ou, equivalentemente, do total que a sociedade ofertou de benefícios. 
últimos dois decis de renda continuam contribuindo mais que recebendo em contraposição aos oito primeiros, e a classe média continua sendo a principal beneficiária.

\section{Discussão}

Com o objetivo de avaliar equidade de renda no acesso ao ensino superior no Brasil, aplicamos a metodologia de Barbaro (2005) que calcula a transferência líquida de benefícios relacionados ao ensino superior entre as diversas classes de renda brasileiras.

Consideramos que o benefício público geral obtido a partir dos orçamentos públicos federal, estadual e municipal tem distribuição idêntica àquela apresentada pelos estudantes da rede pública pelos decis de renda. Os dados da PNAD 2012 informam que 45\% dos alunos estão nos três últimos decis de renda. Portanto, aproximadamente metade desse benefício público geral, que é ofertado através das universidades públicas, está sendo usufruído pelos $30 \%$ mais ricos. Vale ressaltar que não consideramos aqui a distribuição dos alunos por cursos dentro das universidades e que, tipicamente, ocorre participação maior de alunos de renda alta nos cursos mais prestigiosos, sendo estes, em alguns casos, os de maior custo. Nesse sentido, poderíamos dizer que nosso exercício pode estar subestimando o benefício dos decis de renda superior. Contudo, esse efeito tende a ser minimizado pela lei das cotas para ingresso nas universidades federais a partir de 2012, na medida em que 50\% das vagas das universidades federais deverão ser ocupadas por alunos do ensino médio público, tipicamente de classe média. ${ }^{6}$

Os benefícios que denominamos específicos, mesmo sendo considerados programas mais focalizados em termos de renda, concentram-se nos decis intermediários da distribuição. Apenas 18\% deste total estão nos últimos três decis de renda. Com isso, somando os benefícios gerais e específicos, encontramos $38 \%$ deles concentrados nessa parcela da população com maior renda.

6 A Lei $n^{\circ} 12.711 / 2012$ garante a reserva de $50 \%$ das matrículas por curso e turno nas 59 universidades federais e 38 institutos federais de educação, ciência e tecnologia a alunos oriundos integralmente do ensino médio público. 
A carga tributária estimada por Pintos-Payeras (2010) e utilizada neste estudo é apenas ligeiramente regressiva. Quando aplicada à renda apurada na PNAD, gera uma distribuição do total de tributos muito similar à distribuição de renda brasileira, que é extremamente desigual. Mais de $63 \%$ da renda está concentrada nos 30\% mais ricos. Como a contribuição de cada família é apenas uma fração constante do total de tributos, sua distribuição segue a distribuição da renda brasileira.

A combinação de mais contribuições e menos benefícios, proporcionalmente, faz com que os últimos dois decis de renda financiem os bens públicos relacionados à educação superior dos oito primeiros. Dito de outra forma, observamos no caso brasileiro a transferência líquida desses recursos dos $20 \%$ mais ricos para o restante da população. Portanto, vê-se que, ao considerar apenas a parcela do orçamento público relativa ao ensino superior, essa transferência líquida atenua a significativa desigualdade de renda presente no caso brasileiro.

Destaque-se ainda que a população que poderíamos caracterizar como classe média brasileira seria a principal beneficiária líquida. A parcela que vai do 4 o ao 7 o decil agrega $75 \%$ do total de benefícios líquidos. Com isso, do ponto de vista de equidade de renda, uma das questões que se coloca é como promover a priorização da política nos primeiros três decis de renda. Lembremos que esses domicílios mais pobres (e geralmente com menor qualificação) não têm sequer $10 \%$ dos alunos do ensino superior.

Observe-se que esses resultados não se alteram se considerarmos as cargas tributárias estimadas em Carvalho et al. (2013) e Silveira et al. (2013). Os últimos dois decis de renda continuam contribuindo mais que recebendo em contraposição aos oito primeiros, e a classe média continua sendo a principal beneficiária.

Visando focalizar a política de cotas para ingresso nas universidades federais nos menos favorecidos, a legislação estabelece um corte de renda de um salário-mínimo e meio per capita para metade das vagas das cotas. Como esse limite é bastante superior ao 3o decil de renda (0,61 salário-mínimo), avaliamos que, apesar de colaborar, não será tão efetivo no sentido de ampliar a participação nos três primeiros decis de renda. Obviamente, a ausência de representantes dessas faixas de renda relaciona-se com diversos fatores, entre eles, o insucesso na educação básica. 


\section{Referências}

BARBARO, S. Equity and efficiency considerations of public higher education, Springer, v. $557,2005$.

BEVIA, C.; ITURBE-ORMAETXE, I. Redistribution and subsidies for higher education. The Scandinavian Journal of Economics, 321-340, 2002.

BOVENBERG, A. L.; JACOBS, B. Redistribution and education subsidies are siamese twins. Journal of Public Economics 89(11), 2005.

CANER, A.; OKTEN, C. Higher education in turkey: Subsidizing the rich or the poor? Economics of Education Review, 35, 75-92, 2013.

CARVALHO, D. B; SIOUEIRA, R. B. D.; NOGUEIRA, J. R. B. Características distributivas e impacto de reformas tributárias sobre o bem-estar das famílias no Brasil. Revista Brasileira de Economia, 67 (3), 263-282, 2013.

CREAN, J. F. The income redistributive effects of public spending on higher education. Journal of Human Resources, 116-123, 1975.

FIELDS, G. S. Higher education and income distribution in a less developed country. Oxford Economic Papers, 27 (2), 245-259, 1975.

FRIEDMAN, M. Capitalism and freedom. University of Chicago Press, 2009.

Friedman, M.; FRIEDMAN, R. Free to choose: A personal statement. Houghton Mifflin Harcourt, 1990.

GONZALEZ ROZADA, M.; MENENDEZ, A. Public university in Argentina: subsidizing the rich? Economics of Education Review, 21(4), 341-351, 2002.

GRÜSKE, K.-D. Verteilungseffekte der öffentlichen hochschulfinanzierung in der bundesrepublik deutschland-personale inzidenz im querschnitt und längsschnitt. Bildung, Bildungsfi-nanzierung und Einkommensverteilung, 2, 71-147, 1994.

HANSEN, W. L.; WEISBROD, B. A. Benefits, costs, and finance of public higher education. Markham Publishing Company Chicago, 1969.

HANUSHEK, E. A; LEUNG, C. K. Y.; YILMAZ, K. Redistribution through education and other transfer mechanisms. Journal of Monetary Economics, 50(8), 1719-1750, 2003.

IMMERVOLL, H.; LEVY, H.; NOGUEIRA, J. R.; DONOGHUE, C. O; SIQUEIRA, R. B. D. Simulating Brazil's tax-benefit system using Brahms, the Brazilian household microsimulation model. Economia Aplicada, 10(2), 203-223, 2006.

JAMES, E.; BENJAMIN, G. Educational distribution and income redistribution through education in Japan. Journal of Human Resources, 469-489, 1987.

KHAN, S. R. The income redistributional impact of financing higher education in Pakistan. World Development, 19(9), 1241-1246, 1991.

LEMELIN, C. Short-term redistributive effects of public financing of university education in Quebec. Canadian Public Policy/Analyse de Politiques, 176-188, 1992.

MACHLIS, P. D. The distributional effects of public higher education in New York city. Public Finance Review, 1(2), 35-57, 1973. 
MCGUIRE, J. W. The distribution of subsidy to students in California public higher education. Journal of Human Resources, 11(3), 1976.

MERZ, D. Umverteilungswirkungen der schweizerischen Hochschulpolitik. Ph. D. Thesis, 1982.

PECHMAN, J. A. The distributional effects of public higher education in California: A review article. The Journal of Human Resources, v. 5(3), 361-370, 1970.

PINTOS-PAYERAS, J. A. Análise da progressividade da carga tributária sobre a população brasileira. Pesquisa e Planejamento Econômico, 40(2), 153-186, 2010.

SANTIAGO, P.; TREMBLAY, K.; BASRI, E.; ARNAL, E. Tertiary Education for the Knowledge Society. Technical report, Organisation for Economic Co-operation and Development, 2008.

SILVEIRA, F. G.; REZENDE, F; AFONSO, J. R.; FERREIRA, J. Fiscal equity: distributional impacts of taxation and social spending in Brazil, 2013.

SOO LEE, S.; RAM, R.; SMITH, C. W. Distributive effect of state subsidy to undergraduate education: The case of Illinois. Economics of Education Review, 18(2), 213-221, 1999.

\section{Sobre os autores}

Carlos Renato de Melo Castro - carlos.m.castro@fazenda.gov.br

Secretaria do Tesouro Nacional Brasília-DF, Brasil.

As ideias contidas no artigo são de inteira responsabilidade do autor e não representam a visão institucional da Secretaria do Tesouro Nacional.

ORCID: https://orcid.org/0000-0002-8890-9977.

Maria Eduarda Tannuri-Pianto-tannuri@unb.br

Universidade de Brasilia, Departamento de Economia, Brasília-DF, Brasil.

ORCID: https://orcid.org/0000-0001-9042-4971.

\section{Sobre o artigo}

Recebido em 30 de agosto de 2016. Aprovado em 12 de abril de 2018. 